\title{
BASIS FOR OPTIMAL CHOICE OF HIGH ALLOYED STRUCTURAL MATERIALS USED IN CHEMICAL AND POWER INDUSTRY
}

Six types of high alloyed structural materials widely used especially in power and chemical industry were under study. The experimental programme was focused on the research of materials resistivity against high aggressive media and time variable loading. The paper summarizes results of slow-strain rate test, electrochemical measurements (by means of potentiodynamic method, electrochemical noise measurement and electrochemical impedance spectroscopy) and fatigue test. The investigation was completed by fractographic analysis of failed test specimens. Detailed photo-documentation of specimen fractures was obtained by means of scanning electron microscopy.

Keywords: stainless steels, nickel alloys, corrosion and fatigue testing, SCC.

\section{Introduction}

Corrosion causes the economy of all countries huge claims every year. These losses are especially due to the extraordinary costs of anticorrosive protection and its maintenance, repairs of early cracked facilities, etc. Also the subsequent losses are very essential, e.g., energy loss, materials loss caused by uneconomical applications or as a result of poor knowledge of corrosion. The corrosion losses re-counted as a share of the gross national product are around $4 \%$ [1]. These days, the metal corrosion losses of the Czech Republic can be estimated up to 100 billion CZK per year. Besides the economic losses, it is necessary to emphasize the ecological consequences (e.g., the endangering of the environment due to the aggressive medium escape out of the rusted pipeline), health threat, and endangering the human lives as well. In many cases, the fact that the corrosion is the primary cause of the accident remains undetected.
The experimental programme, the results of which are summarized in the paper, was focused on six types of very noble high alloyed materials: two duplex stainless steels, two austenitic stainless steels, and two nickel alloys. These alloys are often used in power, chemical, and food-processing industries. The aim of the study is to verify the most important characteristics quantifying corrosion resistivity especially in media containing chloride ions, and the fatigue properties of the above mentioned materials [2].

\section{Investigated Materials}

All corrosion-proof materials under study, i.e., duplex stainless steels $\mathrm{X} 2 \mathrm{CrNiMoN}$ 22-5-3 (Uranus $45 \mathrm{~N}$ ) and $\mathrm{X} 2 \mathrm{CrNiMoCuN}$ 25-6-3 (Uranus $52 \mathrm{~N}+$ ), austenitic stainless steels X1CrNiMoCuN 25-25-5 (Uranus SB8) and X1NiCrMoCuN 25-20-7 (Uranus B26), and nickel alloys X1NiCrMoCu 32-28-7 (Nicrofer 3127hMo) and NiCr23Mo16A1 (Nicrofer 5923hMo) were delivered in the form

\begin{tabular}{|l|c|c|c|c|c|c|c|c|c|c|}
\hline Alloy & $\mathrm{C}$ & $\mathrm{Si}$ & $\mathrm{Mn}$ & $\mathrm{Ni}$ & $\mathrm{Cr}$ & $\mathrm{Mo}$ & $\mathrm{Cu}$ & $\mathrm{N}$ & $\mathrm{V}$ & $\mathrm{W}$ \\
\hline UR 45N & 0.026 & 0.356 & 1.343 & 5.070 & 21.800 & 3.130 & - & 0.172 & - & - \\
\hline UR 52N+ & 0.015 & 0.335 & 1.130 & 6.020 & 24.900 & 3.740 & 1.650 & 0.248 & - & - \\
\hline UR SB8 & 0.010 & 0.246 & 0.936 & 25.900 & 25.050 & 4.730 & 1.450 & 0.214 & - & - \\
\hline UR B26 & 0.009 & 0.220 & 0.880 & 24.750 & 20.400 & 6.300 & 0.860 & 0.198 & - & - \\
\hline Nicrofer 3127hMo & 0.008 & 0.040 & 1.510 & 31.050 & 26.650 & 6.340 & 1.160 & 0.207 & - & - \\
\hline Nicrofer 5923hMo & 0.007 & 0.040 & 0.150 & 60.900 & 22.500 & 15.500 & 0.010 & - & 0.150 & 0.010 \\
\hline
\end{tabular}

* J. Kunz ${ }^{1}$, K. Dalikova ${ }^{1,2}$, V. Cihal ${ }^{2}$

${ }^{1}$ Department of Materials, Faculty of Nuclear Sciences and Physical Engineering, Czech Technical University in Prague, Prague 2, Czech Republic, E-mail: jiri.kunz@fjfi.cvut.cz

${ }^{2}$ SVUOM Ltd., Prague 6, Czech Republic 


\section{COMMNICOIIONS}

of blank sheets between 4.5 and $10 \mathrm{~mm}$ thick. In the text below, the abbreviation UR will be used for the alloys type of Uranus.
These sheets were heat treated by solution annealing at about $1050{ }^{\circ} \mathrm{C}$ and subsequent rapid water cooling. The microstructure
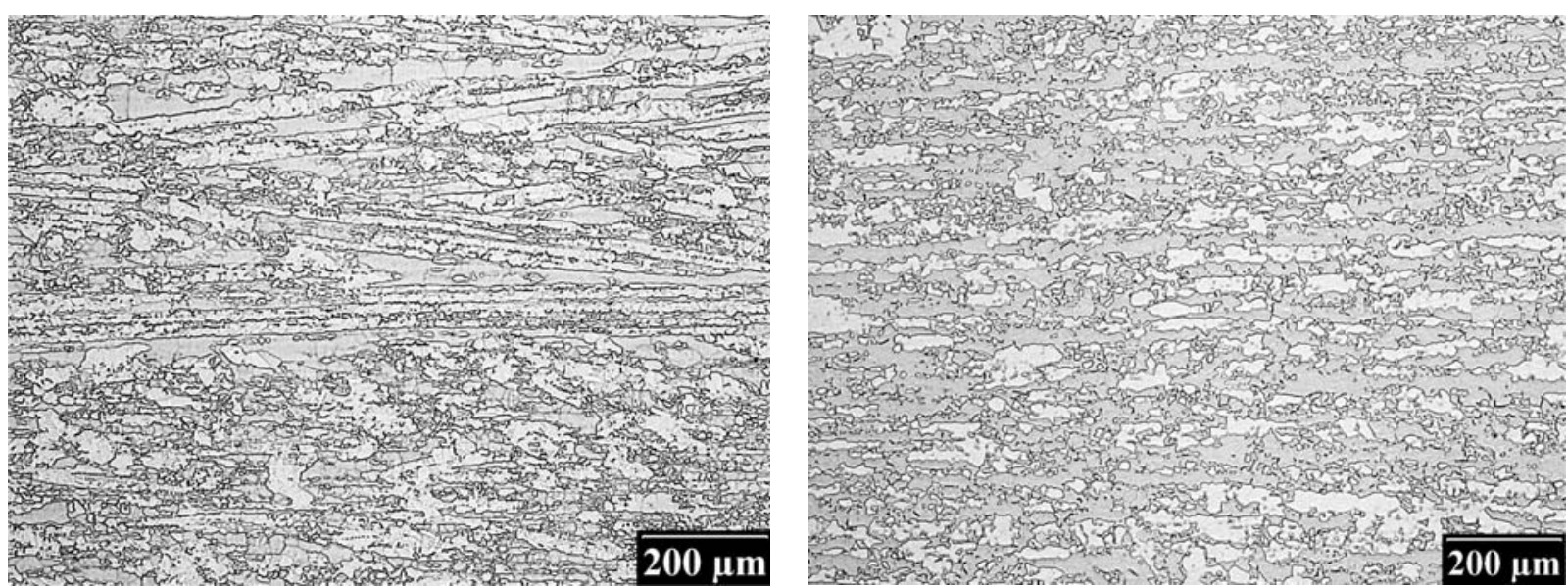

Fig. 1 Microstructure of duplex steels - Uranus $45 \mathrm{~N}$ and $52 \mathrm{~N}^{+}$
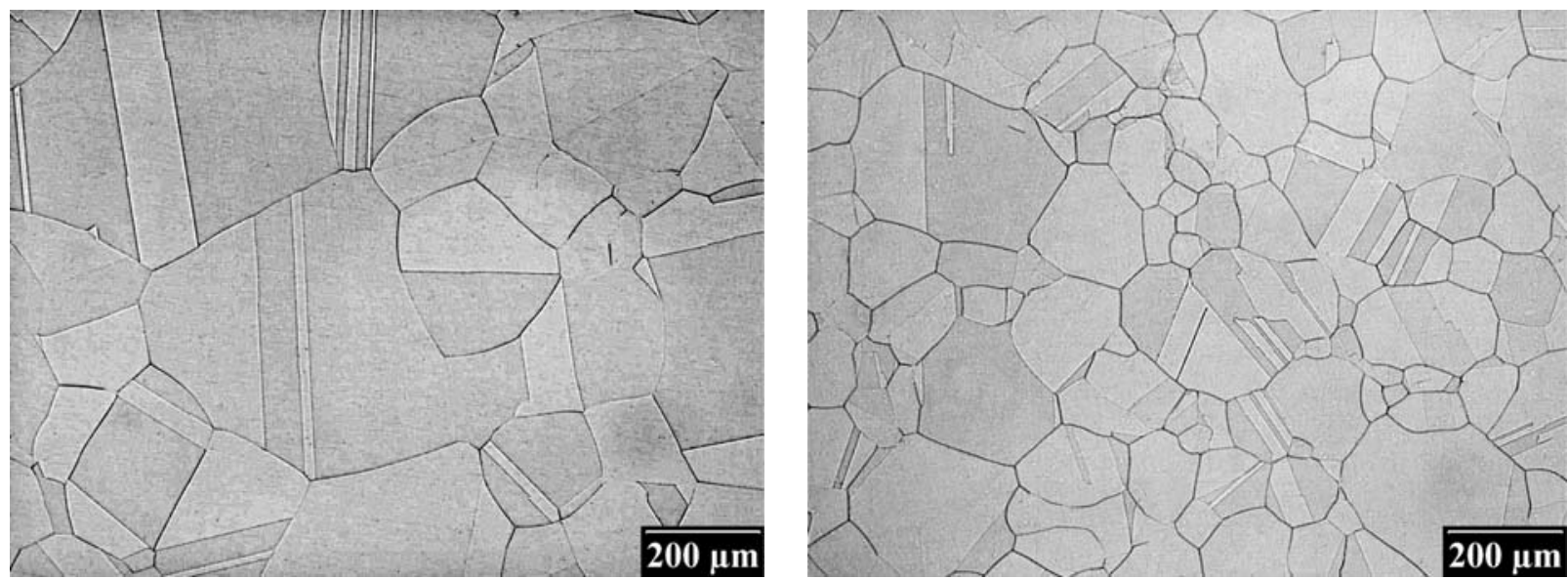

Fig. 2 Microstructure of austenitic steels - Uranus SB8 and B26
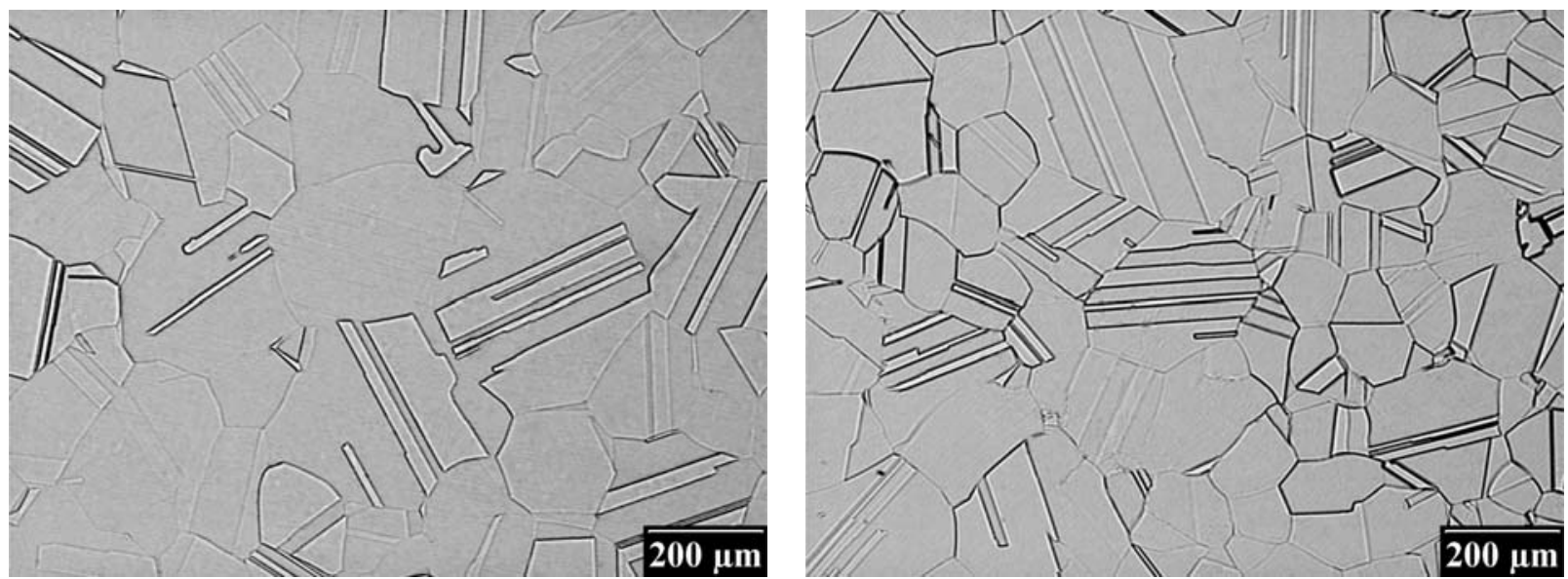

Fig. 3 Microstructure of nickel alloys - Nicrofer 3127hMo and Nicrofer 5923hMo 
of the materials studied by means of light microscopy is documented in Figs 1-3. In comparison with both austenitic steels and Ni-alloys, the microstructure of duplex steels is much more fine.

The chemical composition, $P R E_{N}$ (Pitting Resistance Equivalent Number) and mechanical properties (i.e., yield strength $R_{p} 0.2$ and ultimate tensile stress $R_{m}$ ) of the alloys under study are summarised in Tabs 1 and 2. For this purpose, the following modified formula for $P R E_{N}$ calculation was used [9]:

$$
P R E_{N}=\mathrm{Cr}+3.3(\mathrm{Mo}+0.5 \mathrm{~W})+16 \mathrm{~N} .
$$

$P R E_{N}$ and mechanical properties

Tab. 2

of the alloys under study [3]

\begin{tabular}{|c|c|c|c|c|}
\hline \multirow{2}{*}{ Alloy } & \multirow{2}{*}{ PRE } & \multicolumn{4}{|c|}{ Mechanical Properties } \\
\cline { 3 - 5 } & & $R_{p} 0.2[\mathrm{MPa}]$ & $R_{m}[\mathrm{MPa}]$ & $R_{p} 0.2 / R_{m}$ \\
\hline UR SB8 & 44 & 300 & 600 & 0.50 \\
\hline UR B26 & 44 & 320 & 700 & 0.46 \\
\hline UR 45N & 35 & 515 & 700 & 0.74 \\
\hline UR 52N+ & 41 & 560 & 800 & 0.70 \\
\hline Nicrofer 3127 hMo & 51 & 348 & 734 & 0.47 \\
\hline Nicrofer 5923 hMo & 74 & 429 & 771 & 0.56 \\
\hline
\end{tabular}

\section{Corrosion Testing}

The resistivity to mechanical stress in aggressive media was investigated by slow strain rate test (SSRT). Cylindrical test specimens with a diameter of $2 \mathrm{~mm}$ and working part length $10 \mathrm{~mm}$ were used. The corrosion media used in the experiments $\left(\mathrm{CaCl}_{2}\right.$, $\mathrm{CaCl}_{2}+\mathrm{FeCl}_{3}$, ASTM G28B and the so called "green death" [3]) were selected with respect to the use of these alloys in practice. For comparison, the same tests were carried out in an inert medium (glycerol). Overall, 38 specimens were loaded at strain rate $2.56 \cdot 10^{-6} \mathrm{~s}^{-1}$ and elevated temperature $T=(60 \div 120)^{\circ} \mathrm{C}$. The time to the specimen failure and corresponding maximum

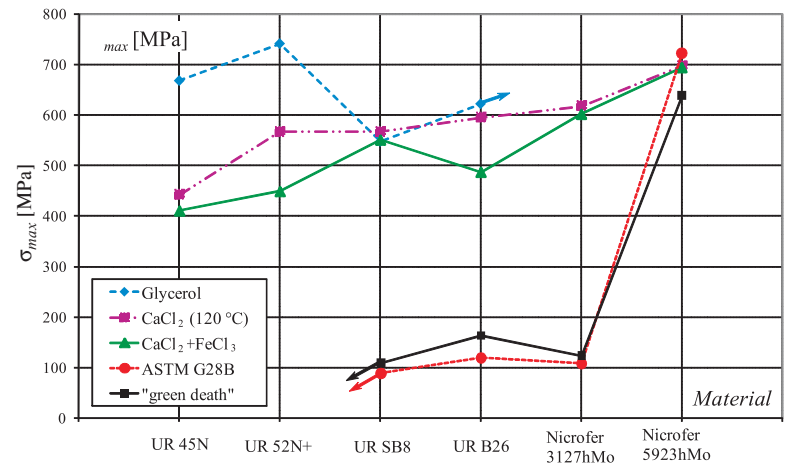

Fig. 4 Maximum stress at specimen failure vs. material in various corrosion media at SSRT load were observed. As an example of the SSRT results, the stress at the specimen failure $\sigma_{\max }$ (relative to the original cross-section) for all alloys under study in various media is presented in Fig. 4. Considerable decrease in $\sigma_{\max }$ due to aggressive media influence is evident especially for both duplex steels, while corrosion resistivity of Nicrofer $5923 \mathrm{hMo}$ is superb even in the most aggressive media, i.e., ASTM G28B and "green death".

One of the electrochemical methods widely used in laboratory practise is potentiodynamic measurement, during which the current response as a function of continuous changes in potential is monitored. Some results of the experiments for austenitic and duplex steels under study tested in $1 \mathrm{~mol} / \mathrm{l} \mathrm{NaCl}$ have been presented previously by Lasek [3].

The electrochemical impedance spectroscopy (EIS) is a powerful tool for examining many chemical and physical processes in solutions as well as in solids. By means of this method, it is possible to determine both the range of materials surface damage in terms of the measured change of its impedance and the corresponding electrochemical reactions of the investigated corrosion process.

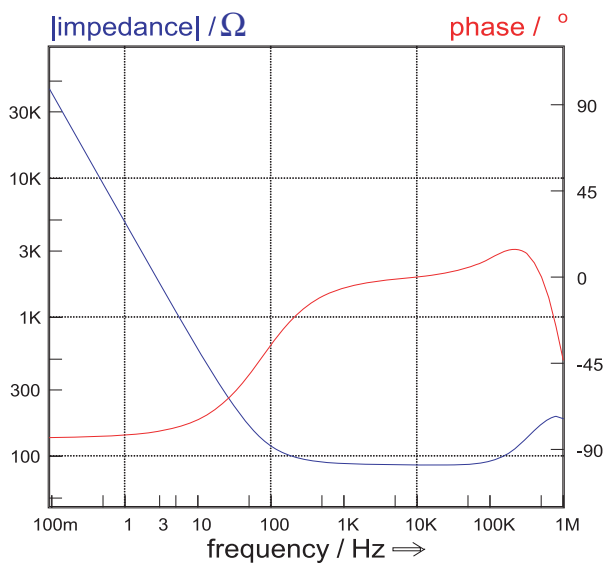

Fig. 5 Bode plot - Uranus B26

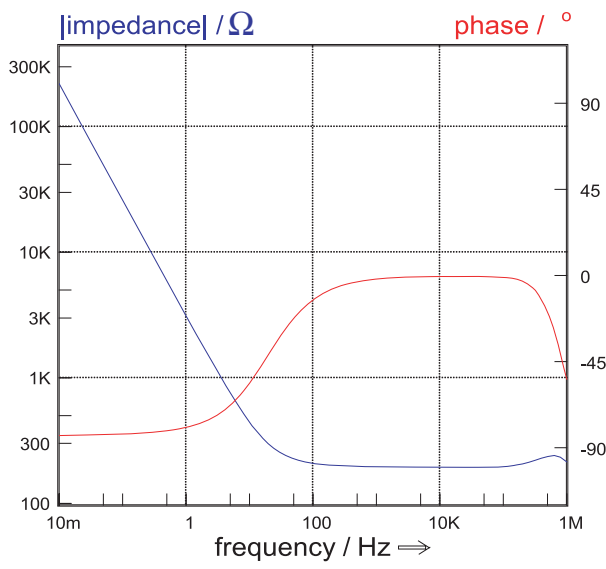

Fig. 6 Bode plot - Uranus $45 \mathrm{~N}$ 
Depending on the shape of the EIS spectrum, a circuit model or circuit description code and initial circuit parameters are assumed and input by the operator. Some of the results from EIS measurements are presented in Figs 5 and 6 for austenitic steel UR B26 and duplex steel UR $45 \mathrm{~N}$ in the form of the so called Bode plots. By means of EIS, the very good stability of passive layers on the surface of studied materials was proved [5].

The real metal surface with structural defects and chemical inhomogeneities does not establish a true stationary state under a constant value of potential or corrosion current. By using of the sensitive electrochemical noise analysis (ENA), it is possible to evaluate the fluctuations that are the result of instantaneous flow of charge between cathodic and anodic reaction sites. For classification of the character and intensity of the running corrosion processes, the frequency and amplitude of the developed electrochemical noise is analysed. The aim of this experiment is to detect the occurrence of localized corrosion attacks (pitting or crevice corrosion, stress corrosion cracking). ENA measurements were carried out in $6 \%$ $\mathrm{FeCl}_{3}$ (according to ASTM G48-76 [4]) at $T=70 \div 85^{\circ} \mathrm{C}$ for the all alloys under study [6] - see Fig. 7. During the experiment, the potential $E_{S C E}$ vs. time $t$ was monitored. This relation gives an objective basis for examining how long the material can survive in this solution (corresponding high potential) before it breaks (drop to the low potentials). From the character of the curves presented in Fig. 7, very good corrosion resistivity of both Ni-alloys is evident

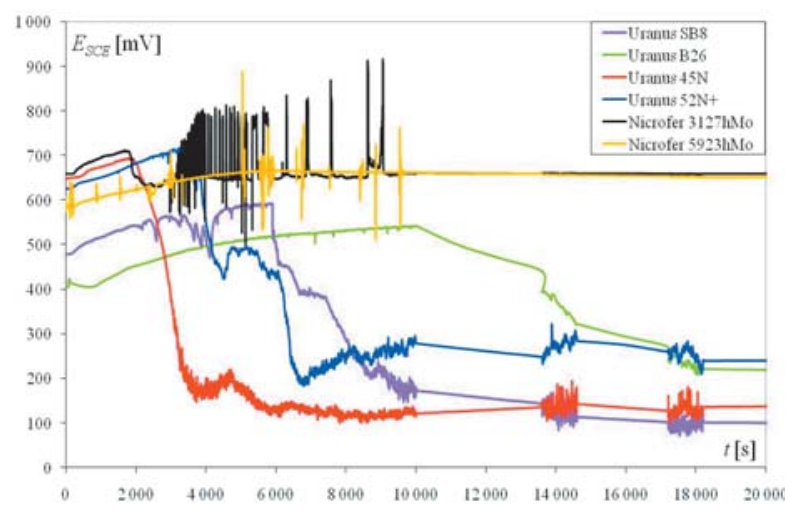

Fig. 7 Results of electrochemical noise analysis of six alloys under study presented in the form of potential $E_{S C E}$ as a function of time $t$

\section{Fatigue Testing}

By means of servo-hydraulic machine INOVA ZUZ 50, the fatigue tests of CT-specimens (width $W=38 \mathrm{~mm}$, length $L=$ $=45.6 \mathrm{~mm}$ and thickness $B=4 \mathrm{~mm}$ ) at constant stress range were carried out. The fatigue crack growth direction was perpendicular to the rolling direction of material sheets. Initial notch in the specimens was extended and sharpened by electro-spark method. The fatigue tests were carried out at room temperature, at stress ratio $R=0.1$ and loading frequency $f=10 \mathrm{~Hz}$. The crack length vs. the number of applied cycles was monitored simultaneously by both optical and potential method during the fatigue testing. The data obtained were statistically processed into the form of the fatigue crack growth rate $v=d a / d N$ as a function of the stress intensity factor range $\Delta K$. The best fitted curves for all six materials under study in the Paris region are presented in Fig. 8.

One set of the specimens was tested until the final fracture. These specimens were subjected to detailed fractographic analysis focused on the study of fatigue failure mechanism. The fatigue tests of the second set of specimens were terminated at the moment the crack of a length of about $a=21.5 \mathrm{~mm}$ was extended; these CTspecimens will be used for corrosion test at constant load.

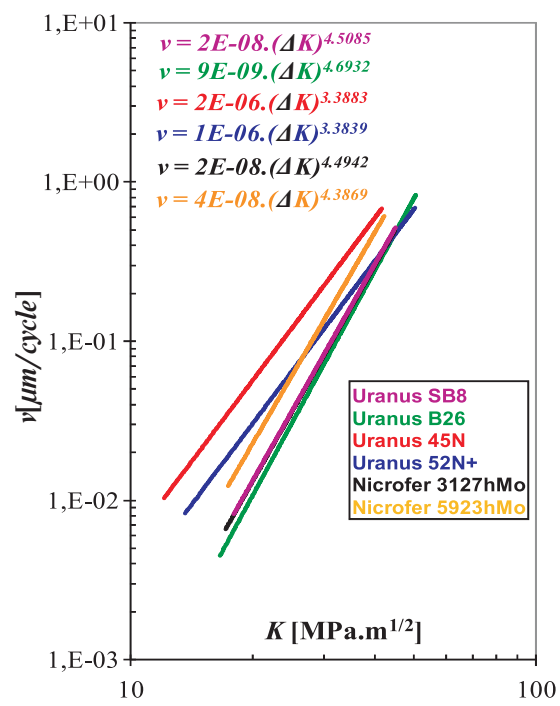

Fig. 8 Results of fatigue tests: crack growth rate $v$ vs. stress intensity factor range $\Delta K$ in Paris region for six high alloyed structural materials

\section{Fractographic Analysis}

The investigation of degradation processes was completed by fractographic analysis of the failed SSRT and fatigue specimens [3]. Fracture micromorphology was studied by means of scanning electron microscope Jeol JSM 840A. The aim of the analysis was to determinate the failure and/or corrosion/fatigue mechanisms, the degradation process type, etc.

By means of qualitative fractographic analysis of fatigued CTspecimens, it was found that the process of fatigue failure could be divided into 3 phases:

- initiation of the fatigue crack in notch root (Fig. 9a),

- transcrystalline propagation of the fatigue crack mainly by striation mechanism (Fig. 9b),

- ductile transcrystalline final fracture (Fig. 9c).

In the lower $\Delta \mathrm{K}$ range, the cleavage facets were also observed on the fatigue fracture surface of specimens of austenite materials (Fig. 9d) [7]. 


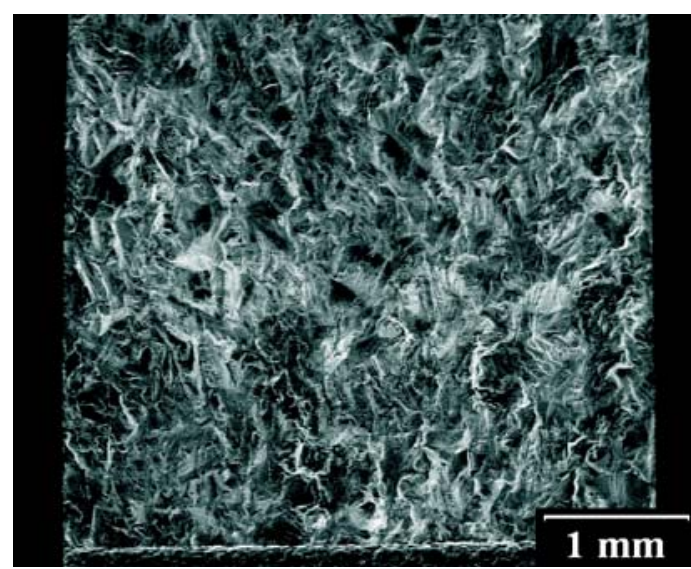

a) fatigue crack initiation

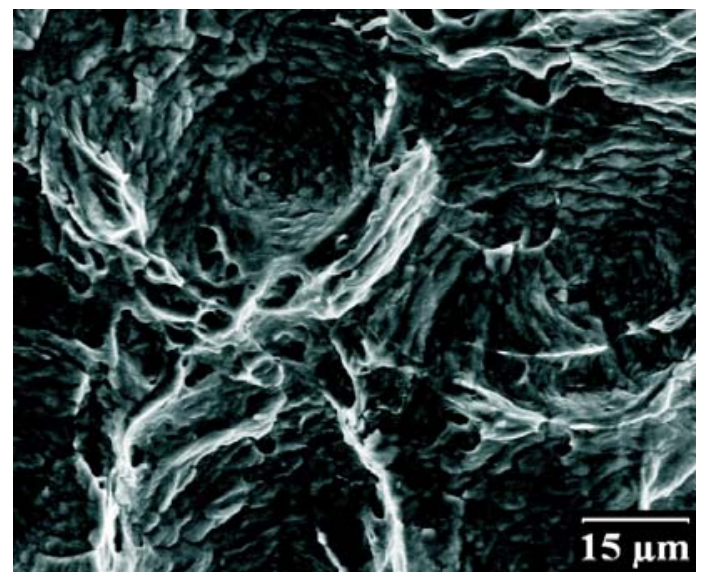

c) transcrystalline ductile final fracture

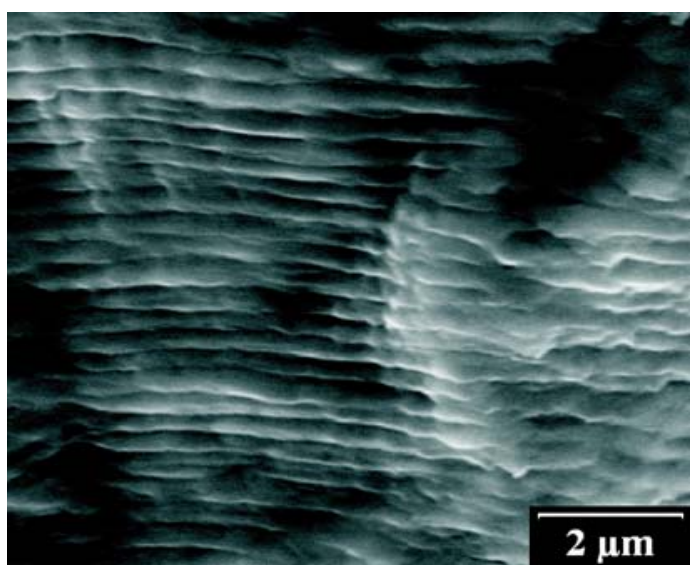

b) transcrystalline ductile striations

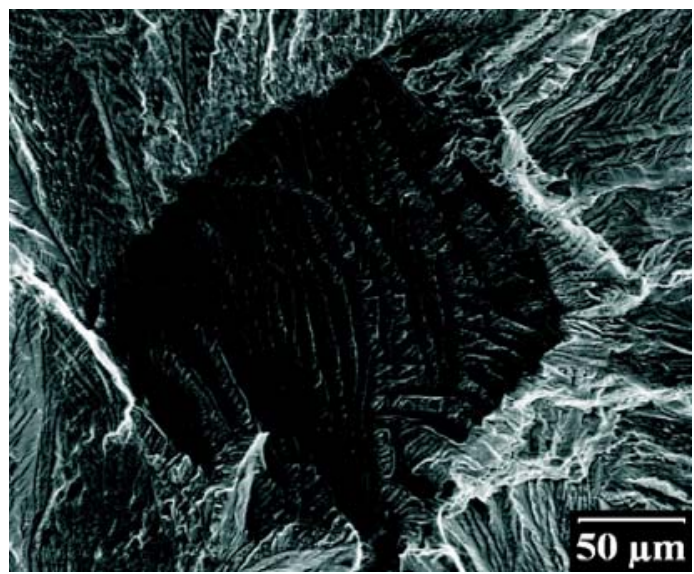

d) cleavage facet in fatigue fracture part

Fig. 9 Austenitic steel Uranus SB8 - typical fracture features of fatigued specimen

\section{Results and conclusions}

The study of degradation processes in six very noble high alloyed materials used mainly in power and chemical industry was carried out. These alloys differ from each other not only by corrosiveness, static mechanical characteristics, and fatigue resistance, but also by their price. The optimal choice of structural material depends on the specific requirements given by corresponding exploitation conditions and user possibilities.

A summary of our substantial experimental results and retrieval information is given in Tab. 3. In this table, four characteristics are evaluated:

a) ratio yield strength $R_{p} 0.2 /$ ultimate tensile stress $R_{m}$ (important performance factor in material specifications, design codes and structural integrity analysis methods),

b) corrosion resistivity in very aggressive media containing chloride ions (based especially on the results of slow strain rate test and electrochemical noise analysis),

c) fatigue endurance in the crack growth period (important factor in the concept of damage-tolerance or fail-safe structure components), d) material price given especially by the price of alloying elements (Mo, Ni, Cr) on the market at the beginning of 2008.

In Tab. 3, the above mentioned characteristics classified by means of the alloy rank within the material group under study (number 1 represents the best alloy according to the given criterion, number 6 refers to the worst one) are supplemented by some practical output notes. It does not mean that the high alloyed material with excellent corrosion resistivity has also, e.g., excellent fatigue properties, i.e., time variable mechanical loading endurance, etc. The presented data represent an objective information basis for the optimized selection of a suitable structural material for specific applications and they identify some limitations from both the engineering and economic point of view.

\section{Acknowledgement}

This research has been supported by reserch project MSM6840770021. Special thanks also to OAD for financial support. 
Summary of main experimental results obtained, economic aspects and practical outputs for six high alloyed materials under study

Tab. 3

\begin{tabular}{|c|c|c|c|c|c|}
\hline Material & $\begin{array}{l}\text { Elastic power } \\
\text { supply }\end{array}$ & $\begin{array}{c}\text { Corrosion Prope } \\
\text { rties* }\end{array}$ & $\begin{array}{c}\text { Fatigue } \\
\text { Properties }\end{array}$ & Price & Recommended Application [8] \\
\hline UR SB8 & 4 & 4 & $2 \div 3$ & 3 & \multirow{2}{*}{$\begin{array}{l}\text { Process equipment for all but strong reducing } \\
\text { and hot sulphuric acids; piping and heat } \\
\text { exchangers handling ambient seawater; FGD } \\
\text { absorbers and paper bleach equipment } \\
\text { operating at moderate Cl-pH-T conditions. }\end{array}$} \\
\hline UR B26 & 6 & 3 & 1 & 4 & \\
\hline UR $45 \mathrm{~N}$ & 1 & 6 & 6 & 1 & \multirow{2}{*}{$\begin{array}{l}\text { Pressure vessels, piping, pumps and valves } \\
\text { where strength and weight are factors along } \\
\text { with resistance to stress corrosion and fatigue; } \\
\text { general purpose heat exchanger tubing. }\end{array}$} \\
\hline UR $52 \mathrm{~N}+$ & 2 & 5 & $4 \div 5 * *$ & 2 & \\
\hline Nicrofer 3127 hMo & 5 & 2 & $2 \div 3$ & 5 & $\begin{array}{l}\text { FGD systems; fine chemicals synthesis, } \\
\text { phosphoric acid production; organic acids } \\
\text { and esters synthesis; waste sulphuric acid } \\
\text { recovery; petroleum production and } \\
\text { refining sulphuric acid coolers. }\end{array}$ \\
\hline Nicrofer $5923 \mathrm{hMo}$ & 3 & 1 & $4 \div 5 * *$ & 6 & $\begin{array}{l}\text { Components inorganic processes in volving } \\
\text { chlorides; digesters and bleaching plants in } \\
\text { the pulp and paper industry; scrubbers, } \\
\text { reheaters; dampers; FGD systems; equipment } \\
\text { and components in sour gas service. }\end{array}$ \\
\hline
\end{tabular}

Notes:

FGD -FlueGasDesulphurization

*) Corrosionpropertieswere evaluatedintermsof ENA and SSR T resultsinvariouscorrosionmedia withdifferentnumber of Clions (e.g., $\mathrm{CaCl}_{2}, \mathrm{CaCl}_{2}+\mathrm{FeCl}_{3}$, "greendeath",ASTM G28B)atelevatedtemperatures $105 \div 120{ }^{\circ} \mathrm{C}$.

**) Fatigue properties are markedly depending on $\Delta K$.

\section{References}

[1] ANON.: Fracture Costs US Industry \$119 000 Million Every Years. Int. J. Fatigue, 5, 3/1983, p. 176.

[2] Stainless Steel Grades. Creusot-Loire Industrie (Creusot-Marrel) - promotional material.

[3] DAliKOVA, K., KUNZ, J., CIHAL, V.: Stress Corrosion Cracking at Slow Strain Rate Test of High Alloyed Ni-Cr-Mo Steels and Nickel Alloys, Proc. of 1st Int. Conf. Corrosion and Material Protection. SVÚOM Praha 2007, p. 6, (CD ROM).

[4] LASEK, S.: Pitting Corrosion of High Alloyed Stainless Steels (in Czech), Dissertation thesis, Ostrava 1999, p. 126, VSB-TU Ostrava.

[5] SILVERMAN, D. C., KENDIG, M.W., SCULLY, J., Eds.: Electrochemical Impedance: Analysis and Interpretation, ASTM STP 1188, ASTM 1993, p. 471.

[6] DALIKOVA, K., LINHARDT, P., CIHAL, V., KUNZ, J.: Corrosion Testing of High Alloyed Structural Materials Used in Power Industry, Proc. of Workshop 2008, Part A., CTU Prague, 2008, pp. 228-229.

[7] DALIKOVA, K., KUNZ, J., SIEGL, J.: Fractographic Analysis of Fatigue Fractures of High Alloyed Austenitic and Duplex Steels (in Czech), Proc. of Letna skola unavy materialov 2008, IX. rocnik (Oscadnica), Zilinska univerzita, 2008, pp. 147-150.

[8] High Performance Stainless Steels. www.stainless-steel-world.net/pdf/11021.pdf, 94 p.

[9] Calculation of pitting resistance equivalent numbers (PREN). http://www.bssa.org.uk/topics.php?article=111. 